Editorial

\title{
Materials Research - rigorosa, mas justa e educativa!
}

A Materials Research - MR, já está indexada em várias bases de referências, incluindo a SCIELO Scientific Electronic Library Online - que, produz a versão eletrônica completa da mesma, disponível no endereço www.scielo.br/mr. A SCIELO é a equivalente brasileira do Institute of Scientific Information e, após rigorosa seleção, deverá indexar aproximadamente cem revistas dedicadas à ciência e tecnologia, dentre mais de quinhentas regularmente editadas no Brasil. Esse fato espelha a qualidade da $M R$.

Alem das três sociedades científicas fundadoras e duas parceiras, estamos na expectativa da criação da Sociedade Brasileira de Pesquisa em Materiais (SBPMat), que passará a ser mais uma entidade parceira da $M R$, com claro efeito sinérgico. A fundação da SBPMat dependerá das sugestões apresentadas em diversas reuniões que estarão ocorrendo nos meses de agosto e setembro em São Paulo, Rio de Janeiro, Belo Horizonte, Canela, Joinville, e Recife. As propostas geradas nesses encontros deverão ser consolidadas e apresentadas na Assembéia geral do XIV CBECIMAT, em Águas de São Pedro, SP, no início do mês de dezembro.

Foram submetidos aproximadamente 1.100 abstracts ao XIV CBECIMAT, recorde absoluto, que mostra o pulso da Ciência e Engenharia de Materiais no Brasil. Dessa rica carteira de trabalhos deveremos criteriosamente selecionar artigos para publicação nos primeiros números do próximo ano.

Excluindo-se os três números especiais da $M R$, a média geral dos tempos de publicação para artigos submetidos diretamente ao editor principal é de 7 meses, incluindo as diligências sugeridas pelos assessores e editor. Nosso recorde foi 46 dias com um máximo de 336 dias. Para acelerar ainda mais o processo de julgamento de artigos, passamos a consultar possíveis assessores antes de encaminhar os artigos completos, sempre que possível em forma eletrônica.
Dos artigos submetidos à publicação a $M R$, aproximadamente 50\% têm sido aceitos, após sugestões e correções dos nossos assessores.

Já decidimos alterar o nome fantasia da $M R$ de Revista Brasileira de Materiais para Revista IberoAmericana de Materiais. O objetivo é ampliar o espectro da $M R$ e fortalecê-la com artigos, revisores e assinantes da Espanha, Portugal e América Latina. Para isso estamos ampliando nosso corpo editorial com renomados cientistas desses países. Já estamos consultando alguns pesquisadores de alto calibre científico e reputação que estejam dispostos a colaborar com a revista, mas ainda devemos ampliar esse quadro e aceitaremos suas sugestões. Na próxima edição da $M R$, em outubro, estaremos incluindo os novos editores ibero-americanos e também renovando parcialmente o corpo editorial nacional.

Agradecemos o Departamento de Engenharia de Materiais - DEMa/ UFSCar pelo auxílio com as despesas de correio, fax e telefone; do NIT/UFSCar pela criação e manutenção da home-page e às secretarias da $\mathrm{ABC}, \mathrm{ABPol}$ e $\mathrm{ABM}$, que têm nos auxiliado na divulgação e no gerenciamento das assinaturas e dos recursos financeiros. $\mathrm{O}$ financiamento para a editoração, produção e impressão deste oitavo número da $M R$ foi proveniente da FAPESP - Fundação de Amparo a Pesquisa do Estado de São Paulo.

Caro leitor, o convocamos a assinar e publicar na $M R$ ! O objetivo da revista é divulgar e demonstrar a qualidade da produção científica nacional (e no futuro, ibero-americana) na área de materiais. Nossa política editorial é pautada por análise rigorosa, mas justa e educativa!

Cordialmente

Edgar Dutra Zanotto

Editor Principal

30-07-2000 